\title{
Internal migration and unmet need for family planning in Cotonou,
}

\section{Benin Republic}

\section{Boladé Hamed Banougnin ${ }^{1}$, Adeyemi O. Adekunle ${ }^{2}$, Adesina Oladokun $^{2}$ \\ \& Mouftaou Amadou Sanni ${ }^{3}$}

${ }^{1}$ Pan African University, Life and Earth Science Institute (Including Health and Agriculture),

University of Ibadan, Ibadan, Nigeria

${ }^{2}$ University College Hospital, Department of Obstetrics and Gynaecology,

University of Ibadan, Ibadan, Nigeria.

${ }^{3}$ Ecole Nationale de la Statistique, de la Planification et de la Démographie,

Université de Parakou, Parakou, Bénin

Email: Hamed.Banougnin@outlook.com

\begin{abstract}
Context/Background: Evidence shows that addressing the unmet need for FP of vulnerable groups such as rural-to-urban migrants is another alternative to lowering fertility in developing countries. This study examines how migration affects unmet need in Cotonou.

Data Source and Methods: We employed multinomial logistic regression using 2012 Benin Republic Demographic and Health Survey data concerning 827 married women aged I5-49 years and residing in Cotonou.

Findings: Findings show that recent migrants were less likely to have an unmet need than non-migrants. Then, earlier migrants and non-migrants had similar odds of unmet need. After adjusting for socioeconomic variables, the risks of unmet need for spacing and limiting among recent migrants decreased and increased, respectively, by $7 \%$. Earlier migrants became significantly less likely to have an unmet need for spacing births than non-migrants.

Conclusion: The odds of unmet need are lower among migrants than non-migrants, but complementary research on migrants' fertility in Cotonou is necessary before any conclusion.
\end{abstract}

Keywords: Migration; unmet need; family planning; Cotonou; Benin Republic

\section{Introduction}

In recent years, fertility has declined in virtually all major areas of the world, but much more slowly in sub-Saharan Africa countries (Casterline, 2017). In Africa, where fertility levels are the highest of any major area (Casterline, 2017; Casterline \& AgyeiMensah, 2017; Gerland et al., 2017), the total fertility rate has fallen from 4.9 children per woman in 20052010 to 4.7 children per woman in 2010-2015 (United Nations, 2015). The slow pace of fertility decline is mostly associated with unmet needs for safe and effective contraception among women who want to avoid or space pregnancies (Ayad \& Hong, 2009; Garenne, 2013; Mutuku, 20I3; Tadesse et al., 2013). During the transition from high to low fertility, unmet need for family planning is low at first, when large families are the norm. It then increases as fertility starts declining and drops when low fertility is achieved. Benin Republic is at an intermediate stage: the unmet need for family planning increased while fertility declined, especially in 2006-20I2 (INSAE \& ICF International, 20 I3; Sanni, 20 I I).

Contraception and unmet need levels vary across countries of the world, the lowest contraception and highest unmet need, being in sub-Saharan Africa (Ashford, 2003; Moreland et al., 2010). Benin Republic has one of the highest levels of unmet need for family planning and a very low contraceptive prevalence rate in the world (ICF International, 20I8). In 20I2, about one-third (32.6\%) of married women had an unmet need for family planning, and less than $8 \%$ of them were using modern contraceptive methods (INSAE \& ICF International, 20I3). Compared to six years ago, the prevalence of unmet need for family planning represents an increase of $19.4 \%$. Unlike the vast majority of the countries with DHS reports, unmet need for contraception was slightly higher in urban (33.2\%) than rural areas (32.1\%) of Benin Republic (ICF International, 20I8). In general, the evidence suggests 
highest levels of awareness and contraceptive use and consequently, lowest unmet need prevalence among urban inhabitants (Khan et al., 2007; Obago, 20I3; Winter et al., 2016); which is not the case in Benin Republic. Populations living in rural locations in most countries are characterized by limited availability of, or access to, appropriate reproductive health-care services compared with urban dwellers (Chintsanya, 2013). So, the reproductive health status is usually poorer among rural than among urban inhabitants.

Moreover, urbanization rate has increased on average by $1.5 \%$ in sub-Saharan Africa over the period from 2000 to 2010 according to the United Nations (20/4) estimations. In Benin Republic, the urbanization rate has increased from $34 \%$ in 1990 (United Nations, 20I4) to $45 \%$ in 2013 (INSAE, 2016). The continuing out-migration from rural areas and small cities forms part of the increasing urbanization (Engel et al., 2017). Migration from rural areas to towns and cities is shifting the rural-urban balance of the population of Benin Republic (Engel et al., 2017). In consequence, the urbanization rate of the country will probably reach $61 \%$ according to demographic projections of the United Nations (20I4). On the other hand, the percentage of women with unmet need for family planning has paradoxically increased between 2006 and 20I2, with its highest level in urban areas (INSAE \& ICF International, 2013). The vulnerability of migrants in cities may account for the fact that unmet need for family planning is higher in urban than rural areas. Indeed, migration to urban centres constitutes a fundamental change in environment and lifestyle; which may be associated with increased risky sexual behaviour, unintended and unwanted pregnancies (Brockerhoff \& Biddlecom, 1999; Greif \& Dodoo, 201I; Greif et al., 20II; Sudhinaraset et al., 20I2). In this regard, it is critical to know how migrants contribute to the unmet need for family planning in cities.

This study examines the extent to which migration to Cotonou, the largest city of Benin Republic, affects the unmet need for family planning. Solving unmet need issue helps to prevent unintended pregnancies, reduce unwanted births and unsafe abortions (Casterline et al., 2003; Rossier, 2007; Shah \& Åhman, 2012; Casterline \& El-Zeini, 2014; Rossier et al., 2014; Sedgh et al., 2016; Rossier \& Corker, 2017). It consequently aims to improve maternal and child health (Addai, 2000; Shaw et al., 2006; Fotso et al., 2009; Ahmed et al., 20/2), especially among migrants who are among the most vulnerable groups (Zheng \& Lian, 2005). Furthermore, this research is relevant in the sense that no study in Benin Republic (to the best of our knowledge) has investigated whether migration affects the unmet need for family planning.

\section{Literature review and hypotheses}

Empirical research has shown that migration can be a life-changing event with profound consequences for sexual and reproductive health (Brockerhoff \& Yang, 1994; Tam, 1994; Brockerhoff, 1995; Rutstein, 2002; Benza et al., 2017; Gerland et al., 2017; Karra et al., 2017; Mberu et al., 2017). Migration from rural to urban areas is likely to increase access to and utilization of contraception (McKinney, 1993; Tam, 1994; Subaiya, 2007; Greif \& Dodoo, 201I; Sudhinaraset et al., 20I2) and thereby, decreasing the unmet need for family planning. Rural-to-urban migrants often remain in close contact with urban native family and friends. They can thus play a role in the diffusion of urban contraception and fertility practices in their rural communities of origin (Ochako et al., 2016; Selassie, 2017). Shittu and Akinyemi (2017) carried out a study in an urban community of Osun state, Nigeria, in which they highlighted the positive influence that Hausa migrants had in improving contraceptive uptake in their rural home areas. They also found that having kin who migrated to larger cities - in comparison with the study location (an urban place of Osun state, Nigeria) - was associated with higher chances of knowledge and use of modern contraceptive methods. In addition, in urban areas, mass education changes the values and costs of children within the family and introduces a Western family model into society (Westoff et al., 20I3). This affects migrants' sexual and reproductive behaviours.

Kamruzzaman and Hakim (2015) found in Bangladesh that urban areas provide greater exposure to information about family planning and fertility practices through print and broadcast media. The authors also confirmed that urban areas provide a greater range and supply of reproductive health services and distribution outlets than rural areas. Migrants to urban areas, however, do not immediately have better access to information and services. They rather accumulate knowledge over time as they learn more about their new environment and expand their range of social contacts (Uprety et al., 2016). Based on these findings, we expect that in a relatively short-term, migrants in Cotonou are more likely to have an unmet need for family planning than non-migrants in Cotonou (Hypothesis la). Then, with time passing, we expect that migrants and non-migrants in Cotonou would have an almost similar risk of having an unmet need for family planning (Hypothesis Ib). Indeed, migration from rural areas and small cities to largest cities can affect contraceptive knowledge and use through changes in both supply and demand and consequently, unmet need for family planning (Cau, 2016). 
Secondly, in examining the relationship between migration and unmet need for family planning, one has to consider the possibility of selective migration. Migrants are not randomly drawn from the populations in which they originally live. They are rather often selected for attributes that are associated with desired family size and contraceptive use (Tam, 1994; Lindstrom \& Hernández, 2006; Khan et al., 2016). Migrants in largest cities often have higher socio-economic status. They usually have a higher educational level, are more likely to delay marriage, have a lower pre-migration fertility and usually participate in gainful employment. Their higher socio-economic status affects positively attitudes towards family planning and reduce the risk of unmet need for contraception (Ochako et al., 2016). The positive selection may occur according to observable characteristics such as age, educational level as well as unobserved characteristics such as media exposure and religion. Consequently, we expect that after adjusting for socio- economic and demographic backgrounds, the risk of unmet need among migrants in Cotonou is similar to that of nonmigrants in Cotonou (Hypothesis 2).

Thirdly, certain migrations can cause spousal separation, which may result in delayed childbearing, especially in the case of job or school migration (Brockerhoff, 1995; Chattopadhyay et al., 2006; Ogawa, 2015; Cau, 2016). In such a situation, the changes relative to migration events induce low fertility and high contraceptive use, at least in a relatively short-term. This is what many researchers on fertility-migration studies (Brockerhoff \& Yang, 1994; Brockerhoff, 1995; Beine et al., 2013; Khanal et al., 20I3; Rokicki et al., 20I4; Khan et al., 2016) have called "disruption effects". The disruption model found support in many studies, especially initially in a work carried out by Goldstein and Tirasawat (1977) in Thailand. They found that the lower fertility among migrants is mostly due to disruption effects. Later, Moreno (1993) confirmed in northeastern Brazil that there was support for the disruption hypothesis in arguing about the high likelihood of contraceptive use among migrants. In this study, we also consider the possibility of disruption effects of migration on fertility. We propose that migrants, especially those who spent less time in Cotonou, may presumably have a lower risk of unmet need than non-migrants (Hypothesis 3).

\section{Data and methods \\ Source of data}

This study drew on data collected from 2012 Benin Republic DHS. The 2012 Benin Republic DHS used a two-stage cluster design with urban-rural and region as strata. We restricted our analysis to $827(\mathrm{I}, 109$ weighted) married women residing in Cotonou, who reported being sexually active in the last twelve months prior to the survey and who were fecund. During the survey, the household questionnaire included specific questions on lifetime migration. Questionnaire for individual woman contained reproductive health information as well as some socio- economic and demographic information of women of reproductive age. Identification variables such as cluster number, household number, and woman's line number were used to merge information in order to obtain a unique database.

\section{Dependent variable}

The dependent variable of the study was unmet need for family planning. The concept of unmet need for family planning emanated from the 1994 International Conference on Population and Development (ICPD) in Cairo, Egypt. Experts who participated in the ICPD demonstrated that unmet need for family planning was an appropriate indicator of the level of women's reproductive rights (Fincher, 1994).

In this analysis, unmet need for family planning variable had three categories: unmet need for spacing births, unmet need for limiting births and no unmet need for family planning. Among women not using contraception, those who wanted no more children were considered to have an unmet need for limiting births. Those who wanted to delay a pregnancy or were unsure if or when they wanted to become pregnant have an unmet need for spacing births (Bradley et al., 20I2).

\section{Independent variables}

The principal independent variable of the study was migration status. We determined migration status through the following information collected in the household questionnaire (for every member) at the moment of the survey: current place of residence, place of birth, previous residence and duration of residence in the current location. Migrants - in this study - were women living in Cotonou at least six months before the survey and who were residing somewhere else in Benin Republic previously. We then classified migrants into two groups: recent migrants and earlier migrants. Migrants who spent up to ten years in Cotonou at the time of the survey were considered as recent migrants. Those who spent more than ten years were considered as earlier migrants. This classification helped to test the gradual process of adaptation as suggested by many researchers when studying the relationship between migration and reproductive behaviours (Ford, 1990; Goldstein et al., 2009).

The other independent variables were: media exposure, educational level, age, number of unions, 
number of living children and religion. The variable of media exposure was a composite indicator including the frequency of reading newspaper or magazine, listening to radio and watching television. We employed principal components analysis (PCA) method to assign the indicator weights that enabled to generate the media exposure index. Filmer and Pritchett (200I) recommended this technique for constructing index values. This procedure first standardizes the indicator variables (calculating zscores); then the factor coefficient scores (factor loadings) are calculated; and finally, for each observation, the indicator values are multiplied by the scores and summed to produce the observation's index value. DHS experts use this technique on behalf of the construction of the DHS wealth index. Here, we used the first factor to represent the media exposure index. The media exposure index had two categories: low exposure and high exposure (see Appendix for the statistical summary).

\section{Methods}

We used multinomial logistic regression models because the categories of the dependent variables are more than two $(0=$ no unmet need for family planning, I = unmet need for spacing births, and $2=$ unmet need for limiting births). The study presented explicative findings in two models. In the first model (Model I), we introduced the key independent variable, migration status, independently to see its influence on unmet need for family planning. Model I enabled to test Hypothesis la or Ib versus
Hypothesis 3. In the final model (Model 2), we added socio- economic and demographic variables as control. Key socio- economic and demographic variables - such as media exposure, educational level, age, number of unions, number of living children and religion - have been found to greatly affect unmet need for contraception (Adebowale \& Palamuleni, 2014; Staveteig, 2016; Wulifan et al., 2016; Machiyama et al., 2017). Model 2 enabled to see whether the risk of unmet need for family planning could be the result of selective migration to Cotonou versus disruptive effect of migration on childbearing (Hypothesis 2 versus Hypothesis 3 ).

\section{Results}

We first reported some descriptive statistics of the variables used in our analysis. Table I indicates that the sample had more migrant women $(62.6 \%$ including recent migrant women and earlier migrant women $-18.8 \%$ and $43.8 \%$ respectively) than nonmigrant women $(37.4 \%)$. At the moment of the survey, about one-quarter (24.5\%) of women had an unmet for spacing births whereas $17.7 \%$ had unmet need for limiting. Most of the respondents (66.5\%) have attained at least a primary education. Approximatively 6 in $10(60.2 \%)$ of the women had a high exposure to media through magazine, radio, and television. At the time of the DHS, the respondents were, on average, 30.7 years old; most of them were non-Muslims (83.3\%); and few of them were nulliparous (6.6\%). More than 8 in 10 (85.3\%) women were in their first marriage.

Table I: Distribution of the dependent variable and independent variables: percentage / mean (standard deviation)

\begin{tabular}{|c|c|c|}
\hline Variables & $\% /$ Mean (SD) & $\mathbf{N}$ \\
\hline \multicolumn{3}{|l|}{ Migratory status } \\
\hline Non-migrant & 37.4 & 415 \\
\hline Recent migrant & 18.8 & 208 \\
\hline Earlier migrant & 43.8 & 486 \\
\hline \multicolumn{3}{|l|}{ Media exposure } \\
\hline Low & 39.8 & 441 \\
\hline High & 60.2 & 667 \\
\hline \multicolumn{3}{|l|}{ Educational level } \\
\hline No education & 33.5 & 372 \\
\hline Primary & 30.3 & 335 \\
\hline Secondary or higher & 36.2 & 401 \\
\hline \multicolumn{3}{|l|}{ Number of unions } \\
\hline Once & 85.3 & 946 \\
\hline More than once & 14.7 & 163 \\
\hline \multicolumn{3}{|l|}{ Number of living children } \\
\hline None & 6.6 & 73 \\
\hline $1-2$ & 48.6 & 539 \\
\hline $3-4$ & 36.0 & 399 \\
\hline 5 or more & 8.7 & 97 \\
\hline \multicolumn{3}{|l|}{ Religion } \\
\hline Muslim & 16.7 & 185 \\
\hline Non-Muslim & 83.3 & 924 \\
\hline Age (in years) & $30.7(6.3)$ & 1109 \\
\hline \multicolumn{3}{|l|}{ Unmet need for FP } \\
\hline Unmet need for spacing & 24.5 & 272 \\
\hline Unmet need for limiting & 17.7 & 196 \\
\hline No unmet need & 57.8 & 641 \\
\hline Total & 100.0 & 1109 \\
\hline
\end{tabular}


Table 2 presents the distribution of unmet need prevalence among migrants and non-migrants, by socio- economic and demographic characteristics. The unmet need was predominantly for spacing births rather than for limiting births, except among a few groups of women. In general, unmet need for spacing was higher among non-migrants $(26.2 \%)$ than among migrants $(21.6 \%)$. And, the percentage of unmet need for limiting was almost the same among migrants (17.9\%) and non-migrants (17.6\%). Chisquare tests show that, among migrants, media exposure, number of living children, number of unions and age had statistically significant associations with unmet need. Among non-migrants, differentials in unmet need existed for all variables except media exposure.
Specifically, the prevalence of unmet need (for spacing and limiting) was significantly higher among migrants with high media exposure $(20.6 \%$ and $13.7 \%$ respectively) than their peers with low media exposure $(23.3 \%$ and $24.3 \%$ respectively). Then, irrespective of the migration status, the higher the number of living children, the higher the prevalence of unmet need for limiting and the lower the prevalence of unmet need for spacing. This pattern of increasing unmet need for limiting and decreasing unmet need for spacing as the number of living children increases was most consistent among nonmigrants than among migrants. And regardless of the migration status, the older women are, the higher the percentage of unmet need for limiting and the lower the unmet need for spacing.

Table 2: Unmet need for FP by socio-economic and socio-demographic variables, according to the migration status.

\begin{tabular}{|c|c|c|c|c|c|c|c|c|c|c|c|c|}
\hline & \multicolumn{6}{|c|}{ Migrant } & \multicolumn{6}{|c|}{ Non-migrant } \\
\hline & $\begin{array}{l}\text { Unmet } \\
\text { need for } \\
\text { spacing }\end{array}$ & $\begin{array}{l}\text { Unmet } \\
\text { need for } \\
\text { limiting }\end{array}$ & $\begin{array}{l}\text { No } \\
\text { unmet } \\
\text { need }\end{array}$ & $\mathrm{N}$ & Khi-2 & $p$-value & $\begin{array}{l}\text { Unmet } \\
\text { need for } \\
\text { spacing }\end{array}$ & $\begin{array}{l}\text { Unmet } \\
\text { need for } \\
\text { limiting }\end{array}$ & $\begin{array}{l}\text { No } \\
\text { unmet } \\
\text { need }\end{array}$ & $\mathrm{N}$ & Khi-2 & $p$-value \\
\hline Media exposure & & & & & $9.012^{\star *}$ & 0.011 & & & & & 1.293 & 0.524 \\
\hline Low & 23.3 & 24.3 & 52.5 & 162 & & & 27.7 & 18.7 & 53.6 & 279 & & \\
\hline High & 20.6 & 13.7 & 65.7 & 253 & & & 25.2 & 16.9 & 57.9 & 415 & & \\
\hline Educational level & & & & & 1.742 & 0.783 & & & & & $16.730^{\star * *}$ & 0.002 \\
\hline No education & 21.1 & 21.1 & 57.8 & 87 & & & 28.2 & 20.3 & 51.6 & 285 & & \\
\hline Primary & 22.7 & 19.4 & 57.9 & 129 & & & 30.5 & 18.5 & 51.0 & 206 & & \\
\hline Secondary or higher & 21.2 & 15.4 & 63.4 & 199 & & & 19.1 & 13.0 & 67.9 & 203 & & \\
\hline Number of unions & & & & & $4.669^{\star}$ & 0.097 & & & & & $9.326^{\star \star \star}$ & 0.009 \\
\hline Once & 22.1 & 15.9 & 62.0 & 343 & & & 24.3 & 18.6 & 57.1 & 602 & & \\
\hline More than once & 19.5 & 27.3 & 53.3 & 71 & & & 38.8 & 11.2 & 50.0 & 91 & & \\
\hline Number of living childrer & & & & & $43.008^{\star \star \star}$ & 0.000 & & & & & $95.970^{\star \star *}$ & 0.000 \\
\hline None & 16.2 & 2.8 & 81.0 & 35 & & & 11.1 & 0.0 & 88.9 & 39 & & \\
\hline $1-2$ & 24.1 & 8.1 & 67.7 & 193 & & & 33.6 & 7.2 & 59.2 & 346 & & \\
\hline $3-4$ & 21.7 & 29.9 & 48.4 & 166 & & & 22.1 & 28.3 & 49.5 & 233 & & \\
\hline 5 or more & 7.6 & 36.4 & 56.0 & 21 & & & 12.6 & 41.2 & 46.2 & 76 & & \\
\hline Religion (Muslim or not) & & & & & 0.658 & 0.720 & & & & & $5.877^{\star}$ & 0.053 \\
\hline Muslim & 23.9 & 20.5 & 55.6 & 52 & & & 30.4 & 10.4 & 59.2 & 132 & & \\
\hline Non-muslim & 21.3 & 17.5 & 61.2 & 363 & & & 25.2 & 19.3 & 55.5 & 561 & & \\
\hline Age group & & & & & $28.527^{\star \star *}$ & 0.000 & & & & & $60.749^{* * *}$ & 0.000 \\
\hline $15-24$ years & 32.5 & 4.9 & 62.6 & 65 & & & 29.4 & 2.6 & 68.1 & 116 & & \\
\hline 25-34 years & 22.6 & 14.3 & 63.1 & 230 & & & 29.7 & 13.7 & 56.6 & 376 & & \\
\hline $35-49$ years & 13.9 & 31.8 & 54.3 & 119 & & & 17.8 & 33.7 & 48.6 & 201 & & \\
\hline Total & 21.6 & 17.9 & 60.5 & 415 & & & 26.2 & 17.6 & 56.2 & 694 & & \\
\hline
\end{tabular}

$\mathrm{N}=$ Weighted number of observations; ${ }^{\star \star \star} \mathrm{p}<0.01,{ }^{\star \star} \mathrm{p}<0.05,{ }^{\star} \mathrm{p}<0.1$

Table 3 presents estimates from multinomial logistic regression models. The p-value for every global model in Table 3 were less than 0.0001 , therefore each global model fits significantly better than a model with no predictors. Findings from Table 3 enabled to test Hypothesis I ( $\mathrm{a}$ and I b), Hypothesis 2 and Hypothesis 3.

We proposed that few time after moving to Cotonou, migrants would be more likely to have an unmet need than non-migrants (Hypothesis la); and then, with time passing, migrants and non-migrants in
Cotonou would have a similar risk of unmet need (Hypothesis Ib). By contrast, Hypothesis 3 proposed that migration to Cotonou could have a disruptive effect on childbearing, implying that migrants - at least in a relatively short-term - may be less likely to have an unmet need than non-migrants. Findings from the first model of Table 3 support Hypothesis 3. Recent migrants were significantly less likely to have unmet need for spacing (Relative Risk Ratio [RRR] = $0.54, \mathrm{Cl}=[0.34 ; 0.88], \mathrm{p}<0.05)$ and limiting (RRR $=0.16, \mathrm{Cl}=[0.08 ; 0.32], \mathrm{p}<0.01$ ) versus no 
unmet need than non-migrants. However, earlier migrants exhibited risks of unmet need for spacing and limiting similar to those of non-migrants; which confirms Hypothesis Ib.

Hypothesis 2 proposed that, taking into account women socio- economic and demographic characteristics, migrants (regardless of how long they have resided in Cotonou) and non-migrants would have similar risks of experiencing unmet need. But, findings from Model 2 in Table are consistent with Hypothesis 3 rather than Hypothesis 2. Indeed, after adjusting for socio- economic and demographic background, the risks of unmet need for family planning have become more significant, with some variations. The risks of unmet need for spacing and limiting

Table 3: Multinomial logistic regression results: Relative risk ratios of having an unmet need for FP.

\begin{tabular}{|c|c|c|c|c|c|c|c|c|}
\hline \multirow{3}{*}{ Variables } & \multicolumn{4}{|c|}{ Model 1} & \multicolumn{4}{|c|}{ Model 2} \\
\hline & \multicolumn{2}{|c|}{ Unmet need for spacing } & \multicolumn{2}{|c|}{ Unmet need for limiting } & \multicolumn{2}{|c|}{ Unmet need for spacing } & \multicolumn{2}{|c|}{ Unmet need for limiting } \\
\hline & RRR & [CI min.; max.] & $\mathrm{RRR}$ & [Cl min.; max.] & RRR & [Cl min.; max.] & $\mathrm{RRR}$ & [CI min.; max.] \\
\hline \multicolumn{9}{|l|}{ Migratory status } \\
\hline Non-migrant (Ref.) & 1 & - & 1 & - & 1 & - & 1 & - \\
\hline Recent migrant & $0.54^{* *}$ & {$[0.34 ; 0.88]$} & $0.16^{\star * *}$ & {$[0.08 ; 0.32]$} & $0.47^{\star * *}$ & {$[0.29 ; 0.78]$} & $0.23^{\star \star \star}$ & {$[0.11 ; 0.47]$} \\
\hline Earlier migrant & 0.75 & {$[0.50 ; 1.12]$} & 0.85 & {$[0.55 ; 1.30]$} & $0.70^{\star}$ & {$[0.46 ; 1.05]$} & 0.74 & {$[0.46 ; 1.20]$} \\
\hline \multicolumn{9}{|l|}{ Media exposure } \\
\hline Low & & & & & 1.03 & {$[0.74 ; 1.42]$} & $1.56^{\star \star}$ & {$[1.07 ; 2.29]$} \\
\hline High (Ref.) & & & & & 1 & - & 1 & - \\
\hline \multicolumn{9}{|l|}{ Educational level } \\
\hline No education (Ref.) & & & & & 1 & - & 1 & - \\
\hline Primary & & & & & 1.12 & {$[0.77 ; 1.64]$} & 1.08 & {$[0.69 ; 1.70]$} \\
\hline Secondary or higher & & & & & $0.71^{*}$ & {$[0.47 ; 1.06]$} & 0.91 & {$[0.56 ; 1.48]$} \\
\hline Age (in years) & & & & & $0.96^{* * *}$ & {$[0.93 ; 0.98]$} & $1.09^{* * *}$ & {$[1.05 ; 1.12]$} \\
\hline \multicolumn{9}{|l|}{ Number of unions } \\
\hline Once (Ref.) & & & & & 1 & - & 1 & - \\
\hline More than once & & & & & $1.79^{\star \star *}$ & {$[1.18 ; 2.70]$} & 0.95 & {$[0.57 ; 1.58]$} \\
\hline \multicolumn{9}{|c|}{ Number of living children } \\
\hline None & & & & & 0.57 & {$[0.21 ; 1.57]$} & $0.05^{\star \star \star}$ & {$[0.01 ; 0.36]$} \\
\hline $1-2$ & & & & & $1.89^{\star}$ & {$[0.90 ; 3.96]$} & $0.32^{\star \star \star}$ & {$[0.17 ; 0.58]$} \\
\hline $3-4$ & & & & & $1.87^{*}$ & {$[0.90 ; 3.89]$} & 0.91 & {$[0.54 ; 1.54]$} \\
\hline 5 or more (Ref.) & & & & & 1 & - & 1 & - \\
\hline \multicolumn{9}{|l|}{ Religion } \\
\hline Muslim & & & & & 1.00 & {$[0.68 ; 1.47]$} & 0.66 & {$[0.39 ; 1.11]$} \\
\hline Non-Muslim (Ref.) & & & & & 1 & - & 1 & - \\
\hline P-value & \multicolumn{4}{|c|}{0.0000} & \multicolumn{4}{|c|}{0.0000} \\
\hline Observations & \multicolumn{4}{|c|}{827} & \multicolumn{4}{|c|}{827} \\
\hline
\end{tabular}

Note : Base outcome $=$ No unmet need for FP; RRR = Relative risk ratios; $\mathrm{Cl}=$ Confidence interval; Ref. $=$ Reference category; ${ }^{\star * *} \mathrm{p}<0.01,{ }^{* *} \mathrm{p}<0.05,{ }^{*} \mathrm{p}<0.1$

births have decreased and increased, respectively by $7 \%$ among recent migrants. Compared to nonmigrants, recent migrants were $53 \%(p<0.01)$ and $77 \%(p<0.01)$ less likely to have respectively unmet for spacing and unmet need for limiting births. Earlier migrants were henceforth $30 \%(p<0.1)$ less likely to have an unmet need for spacing versus no unmet need than non-migrants.

Moreover, some socio- economic and demographic variables - such as media exposure, educational level, age, number of unions and number of living children - had significant influence on unmet need for family planning. Women in their first marriage were 1.79 times $(\mathrm{Cl}=[1.18 ; 2.70], \mathrm{p}<$ 0.01 ) more likely to have an unmet need for spacing than those who were married more than once. Also, women having between one and four living children were about twice $(R R R=1.90, p<0.1)$ more likely to have an unmet need for spacing than nulliparous. By contrast, the risks of unmet need for spacing births decreased among women with secondary or higher education (RRR $=0.7 \mathrm{I}, \mathrm{Cl}=[0.47 ; \mathrm{I} .06], \mathrm{p}<$ $0.1)$ as well as with a one-unit increase in age (RRR = $0.96, \mathrm{Cl}=[0.93 ; 0.98], \mathrm{p}<0.01)$. On the other hand, women were more likely to have unmet need for limiting births versus no unmet need when they have low rather than high media exposure $(\mathrm{RRR}=$ I.56, $\mathrm{Cl}=[1.07 ; 2.29], \mathrm{p}<0.05)$ and as the age rises $(\mathrm{RRR}=1.09, \mathrm{Cl}=[\mathrm{I} .05 ; \mathrm{I} . \mathrm{I}], \mathrm{p}<0.0 \mathrm{I})$. Compared to women having four children or above, nulliparous and those with one or two children were respectively $95 \%(p<0.01)$ and $68 \%(p<0.01)$ less likely to have an unmet need for limiting versus no unmet need. 


\section{Discussion}

This study aims to explore the effect of internal migration on unmet need for family planning among married women aged 15-49 years in Cotonou, the largest city of Benin Republic. The results indicate that migration is significantly associated with unmet need for spacing and limiting births. The analyses show that migrant women were less likely to have an unmet need for family planning than non-migrant women in Cotonou. Moreover, certain socioeconomic and demographic variables - such as education, age, number of unions and number of living children - had significant influence on unmet need for family planning.

First, results show that recent migrants were less likely to have an unmet need for spacing and limiting births than non-migrants. This suggests a disruptive character of migration process in the short-term, which in turn, is itself somehow disruptive of fertility. The disruption effect comes into play by delaying childbearing either by spousal separation or the time taken to adjust at the new environment (Ochako et al., 2016). Explaining lower fertility among recent migrants in Thailand, Goldstein and Tirasawat (1977) argued that a migration itself may be sufficiently disruptive to interfere with childbearing. The authors concluded that socio-economic characteristics of migrants including labour force participation, educational level, and media exposure contribute to lower fertility. Furthermore, Lindstrom and Hernández (2006) have demonstrated in Guatemala that migrants in urban areas had a higher knowledge of contraceptive use than non-migrants whereas Ochako et al. (2016) have found in Kenya higher chances of modern contraceptive use among migrants. The joint effects of high contraceptive practice and lower fertility among migrants can lead to a lower unmet need for family planning among migrants.

Secondly, the results further show that earlier migrants and non-migrants in Cotonou had almost similar risks of experiencing an unmet need for spacing and limiting births. That is, earlier migrants and non-migrants in Cotonou experience about the same level of unmet need for family planning; which is consistent with the gradual process of migrant adaptation. Generally, previous studies on the relationship between migration and contraceptive practice have proved gradual adaptation rather than a rapid adaptation in terms of contraceptive use (Lindstrom \& Hernández, 2006; Rokicki et al., 2014; Cau, 2016). Therefore, we can conclude that there is an evidence of gradual adaptation once disruption effects disappear.

Thirdly, after adjusting for some socio- economic and demographic variables, it appears that migration status is reinforced in determining unmet need for family planning. Compared to non-migrants, earlier migrants were henceforth significantly less likely to have an unmet need for spacing births; which suggests that the disruption effect of migration on childbearing is probably reinforced by the selection effect of migration to Cotonou. The theory of selective migration to large cities states that migrants in large cities are a self-selecting group with characteristics that cause delays in childbearing and increase of contraceptive use (Brockerhoff \& Biddlecom, 1999). One possible explanation for this hypothesis is that women who migrate to Cotonou have specific socio- economic and demographic characteristics associated with low fertility preference. On average, migrants in Cotonou are more educated, have high access to media and usually move to Cotonou for employment, studies or other economic reasons. In addition, the high cost of living in Cotonou also makes migrant women encounter increased family maintenance costs; which may be a source of low fertility desire for additional children and high contraceptive use. The high cost of living in Cotonou plus the selection effect of migration may, in consequence, contribute to the lower unmet need for family planning. Then, as time spent in Cotonou increased, migrants may be more likely to adapt to non-migrants' fertility and contraceptive practices. The selection hypothesis has been supported among Kenyan migrant women in urban areas by Ochako et al. (2016) in terms of modern contraceptive use. Many other studies have confirmed the evidence that migration operates selectively to affect fertility (Beine et al., 20।3; Khanal et al., 20।3; Rokicki et al., 20।4).

Finally, all socio- economic and demographic variables except religion had significant effect on unmet need for family planning. Married women with secondary or higher educational level, at an older age, and without children have lower odds of having an unmet need for spacing births. These findings are in line with empirical evidence from studies aimed at determining how socio-economic characteristics affect unmet need for family planning in sub-Saharan Africa (Ayad \& Hong, 2009; Rossier \& Ortiz, 201I; Casterline \& El-Zeini, 20I4). By contrast, women who got married more than once and those having between one and four living children had higher odds of having unmet need for spacing births. Adebowale and Palamuleni (2014) also found in rural areas of Burkina-Faso that being married more than once increases the likelihood of unmet need. On the other hand, women with low media exposure and at a younger age had higher odds of having unmet need for limiting contrary to those with a high number of living children. These findings are consistent with other studies conducted in sub-Saharan Africa 
(Bizuneh et al., 2008; Khan et al., 2008; Ayele et al., 2013; MacQuarrie, 2014; Staveteig, 2016; Wulifan et al., 2016). For example, in a study conducted in Ethiopia, Bizuneh et al. (2008) concluded that the higher the number of living children, the higher the risk of unmet need for limiting and the lower the risk of unmet need for spacing.

\section{Conclusion}

With the exception of some rare cases, studies on the effects of migration on reproductive and sexual health were limited to the relationship between HIV or condom use and migration (Greif \& Dodoo, 20I I). Furthermore, no study - to the best of our knowledge - has investigated the impact of migration on unmet need for family planning in sub-Saharan Africa, let alone in Benin Republic. The main strength of this study is that it takes into account the effects of migration duration which is determinant to evaluate the adaptation process. It also evaluates the proper effect of selectivity and the disruptive effect of migration to Cotonou. However, the major limitation is the use of one data point which fails to document the occurrence of multiple events over time. This could have led to potential misclassification of unmet need for family planning or migration status. However, with regards to the latter, most migrants in this study reported that they had resided in Cotonou for a duration of time, and therefore the effects of misclassification on unmet need for family planning use are likely minimal. It could also be relevant to address the issue of unmet need for family planning among men in relation with migration.

\section{Reference}

Addai, I. 2000. Determinants of use of maternal-child health services in rural Ghana. Journal of biosocial science, 32, I-I5.

Adebowale, S. A. \& Palamuleni, M. E. 2014. Determinants of unmet need for modern contraception and reasons for non-use among married women in rural areas of Burkina Faso. Etude de la Population Africaine, 28, 499.

Ahmed, S., Li, Q., Liu, L. \& Tsui, A. O. $20 / 2$. Maternal deaths averted by contraceptive use: an analysis of 172 countries. The Lancet, 380, III125.

Ashford, L. 2003. Unmet need for family planning: Recent trends and their implications for programs, Population Reference Bureau Washington, DC.

Ayad, M. \& Hong, R. 2009. Levels and trends of contraceptive prevalence and estimate of unmet need for family planning in Rwanda: Further analysis of the Rwanda Demographic and Health Surveys, 2000ñ2007/08. DHS Further Analysis
Reports No. 67. Calverton, Maryland, USA: ICF Macro.

Ayele, W., Tesfaye, H., Gebreyes, R. \& Gebreselassie, T. 20I3. Trends and determinants of unmet need for family planning and programme options, Ethiopia: Further analysis of the 2000, 2005, and 20II Demographic and Health Surveys. DHS Further Analysis Reports No. 8I. Calverton, Maryland, USA: ICF International.

Beine, M., Docquier, F. \& Schiff, M. 2013. International migration, transfer of norms and home country fertility. Canadian Journal of Economics/Revue canadienne d'économique, 46, |406-1430.

Benza, M., Weeks, J. R., Stow, D. A., López-Carr, D. \& Clarke, K. C. 2017. Fertility and urban context: A case study from Ghana, West Africa, using remotely sensed imagery and GIS. Population, Space and Place.

Bizuneh, G., Shiferaw, S. \& Melkamu, Y. 2008. Unmet need and evaluation of programme options to meet unmet need for contraception in Ethiopia, 2000 and 2005: Further analysis of the 2005 Demographic and Health Survey. DHS Further Analysis Reports No. 62. Calverton, Maryland, USA: Macro International.

Bradley, S. E. K., Croft, T. N., Fishel, J. D. \& Westoff, C. F. 20/2. Revising unmet need for family planning. DHS Analytical Studies No. 25. Calverton, Maryland, USA: ICF International.

Brockerhoff, M. 1995. Fertility and family planning in African cities: The impact of female migration. Journal of Biosocial Science, 27, 347-358.

Brockerhoff, M. \& Biddlecom, A. E. 1999. Migration, sexual behavior and the risk of HIV in Kenya. International migration review, 833-856.

Brockerhoff, M. \& Yang, X. 1994. Impact of migration on fertility in sub-Saharan Africa. Social Biology, $41,19-43$.

Casterline, J. B. 2017. Prospects for Fertility Decline in Africa. Population and Development Review, 43, 3-18.

Casterline, J. B. \& Agyei-Mensah, S. 2017. Fertility Desires and the Course of Fertility Decline in subSaharan Africa. Population and Development Review, 43, 84-III.

Casterline, J. B., El-Zanaty, F. \& El-Zeini, L. O. 2003. Unmet need and unintended fertility: longitudinal evidence from Upper Egypt. International family planning perspectives, I58-166.

Casterline, J. B. \& El-Zeini, L. O. 20I4. Unmet Need and Fertility Decline: A Comparative Perspective on Prospects in Sub-Saharan Africa. Studies in family planning, 45, 227-245. 
Cau, B. M. 2016. Female migration, local context and contraception use in urban Mozambique. African Journal of Reproductive Health, 20, 52-6I.

Chattopadhyay, A., White, M. J. \& Debpuur, C. 2006. Migrant fertility in Ghana: Selection versus adaptation and disruption as causal mechanisms. Population studies, 60, 189-203.

Chintsanya, J. 20/3. Trends and correlates of contraceptive use among married women in Malawi: Evidence from 2000-2010 Malawi Demographic and Health Surveys. DHS Working Papers No. 87. Calverton, Maryland, USA: ICF International.

Engel, E., Richter, D. \& Schüring, J. 20I7. Bénin: vers une transformation rurale inclusive et durable.

Filmer, D. \& Pritchett, L. H. 200I. Estimating wealth effects without expenditure data-or tears: an application to educational enrollments in states of India. Demography, 38, I I5-I 32.

Fincher, R. A. 1994. International Conference on Population and Development. Envtl. Pol'y \& L., 24, 309.

Ford, K. 1990. Duration of residence in the United States and the fertility of US immigrants. International migration review, 34-68.

Fotso, J.-C., Ezeh, A. C. \& Essendi, H. 2009. Maternal health in resource-poor urban settings: how does women's autonomy influence the utilization of obstetric care services? Reproductive Health, 6, 9.

Garenne, M. 2013. Situations of fertility stall in subSaharan Africa. African Population Studies, 23.

Gerland, P., Biddlecom, A. \& Kantorová, V. 2017. Patterns of Fertility Decline and the Impact of Alternative Scenarios of Future Fertility Change in sub-Saharan Africa. Population and Development Review, 43, 21-38.

Goldstein, J. R., Sobotka, T. \& Jasilioniene, A. 2009. The End of "Lowest-Low" Fertility? Population and development review, 35, 663-699.

Goldstein, S. \& Tirasawat, P. 1977. Fertility of migrants to urban places in Thailand.

Greif, M. J. \& Dodoo, F. N.-A. 20II. Internal migration to Nairobi's slums: Linking migrant streams to sexual risk behavior. Health \& place, 17, 86-93.

Greif, M. J., Dodoo, F. N.-A. \& Jayaraman, A. 201 I. Urbanisation, poverty and sexual behaviour: the tale of five African cities. Urban Studies, 48, 947957.

Icf International 2018. The DHS Program STATcompiler. Funded by USAID. STATcompiler. Available from: http://www.statcompiler.com/en/.

Insae 2016. Principaux Indicateurs Socio démographiques et Économiques du Bénin, (RGPH-4, 20I3).
Insae \& Iff International 20I3. Enquête Démographique et de Santé Bénin 20II-20I2. Calverton, Maryland, USA: INSAE/Bénin and ICF International.

Kamruzzaman, M. \& Hakim, M. A. 20I5. Family Planning Practices among Married Women attending Primary Health Care Centers in Bangladesh. International Journal of Bioinformatics and Biomedical Engineering, I, 25 I-255.

Karra, M., Canning, D. \& Wilde, J. 2017. The effect of fertility decline on economic growth in Africa: A macrosimulation model. Population and Development Review, 43, 237-263.

Khan, R., Macquarrie, K. L. D., Nahar, Q. \& Sultana, M. 2016. The men are away: pregnancy risk and family planning needs among women with a migrant husband in Barisal, Bangladesh. DHS Further Analysis Reports No. 98. Rockville, Maryland, USA: ICF International.

Khan, S., Bradley, S. E. K., Fishel, J. \& Mishra, V. 2008. Unmet need and the demand for family planning in Uganda: Further analysis of the Uganda Demographic and Health Surveys, 1995-2006. DHS Further Analysis Reports No. 60. Calverton, Maryland, USA: Macro International.

Khan, S., Mishra, V., Arnold, F. \& Abderrahim, N. 2007. Contraceptive trends in developing countries. DHS Comparative Reports No. 16. Calverton, Maryland, USA: Macro International.

Khanal, M. N., Shrestha, D. R., Pant, P. D. \& Mehata, S. 20 I3. Impact of male migration of contraceptive use, unmet need, and fertility in Nepal: Further analysis of the 20II Nepal Demographic and Health Survey. DHS Further Analysis Reports No. 74. Calverton, Maryland, USA: ICF International.

Lindstrom, D. P. \& Hernández, C. H. 2006. Internal migration and contraceptive knowledge and use in Guatemala. International family planning perspectives, I46-I53.

Machiyama, K., Casterline, J. B., Mumah, J. N., Huda, F. A., Obare, F., Odwe, G., Kabiru, C. W., Yeasmin, S. \& Cleland, J. 2017. Reasons for unmet need for family planning, with attention to the measurement of fertility preferences: protocol for a multi-site cohort study. Reproductive health, I4, 23.

Macquarrie, K. L. D. 2014. Unmet need for family planning among young women: levels and trends. DHS Comparative Reports No. 34. Rockville, Maryland, USA: ICF International.

Mberu, B., Béguy, D. \& Ezeh, A. C. 2017. Internal Migration, Urbanization and Slums in Sub-Saharan Africa. Africa's Population: In Search of a Demographic Dividend. Springer.

Mckinney, B. J. 1993. Impact of rural-urban migration on migrant fertility in Senegal. DHS Working 
Papers No. 6. Columbia, Maryland, USA: Macro International.

Moreland, S., Smith, E. \& Sharma, S. 2010. World population prospects and unmet need for family planning. Washington, DC: Futures Group, 62.

Moreno, L. 1993. Residential mobility and contraceptive use in northeastern Brazil.

Mutuku, A. K. 20/3. Fertility transition and its determinants in Kenya: 2003-2008/9. DHS Working Papers No. 82. Calverton, Maryland, USA: ICF International.

Obago, I. T. 2013. The role of antenatal care in predicting health facility delivery among women in Kenya: Further analysis of data from the 2008-09 KDHS. DHS Working Papers No. 86. Calverton, Maryland, USA: ICF International.

Ochako, R., Askew, I., Okal, J., Oucho, J. \& Temmerman, M. 2016. Modern contraceptive use among migrant and non-migrant women in Kenya. Reproductive health, 13, 67.

Ogawa, N. 2015. Demographic Change in Southeast Asia: Recent Histories and Future Directions edited by Lindy Williams and Michael Philip Guest, Ithaca, NY, Southeast Asia Program Publications, Southeast Asia Program, Cornell University, 2012, 221 pp. Wiley Online Library.

Rokicki, S., Montana, L. \& Fink, G. 2014. Impact of migration on fertility and abortion: evidence from the household and welfare study of Accra. Demography, 5I, 2229-2254.

Rossier, C. 2007. Abortion: an open secret? Abortion and social network involvement in Burkina Faso. Reproductive Health Matters, 15, 230-238.

Rossier, C. \& Corker, J. 2017. Contemporary Use of Traditional Contraception in sub-Saharan Africa. Population and Development Review, 43, 192215.

Rossier, C. \& Ortiz, I. Unmet needs for contraception in formal and informal neighborhoods of Ouagadougou. 6th African Population Conference, 20II. 5-9.

Rossier, C., Senderowicz, L. \& Soura, A. 2014. Do natural methods count? Underreporting of natural contraception in urban Burkina Faso. Studies in family planning, 45, I7|- | 82.

Rutstein, S. O. 2002. Fertility levels, trends, and differentials 1995-1999. DHS Comparative Reports No. 3. Calverton, Maryland, USA: ORC Macro.

Sanni, M. A. 20I I. Niveaux et tendances des besoins non satisfaits deplanification familiale au Bénin: Facteurs explicatifset changements dans le temps. African Population Studies, 25(2).

Sedgh, G., Bearak, J., Singh, S., Bankole, A., Popinchalk, A., Ganatra, B., Rossier, C., Gerdts, C., Tunçalp, Ö. \& Johnson, B. R. 2016. Abortion incidence between 1990 and 2014: global, regional, and subregional levels and trends. The Lancet, 388, 258-267.

Selassie, T. G. 2017. Determinants of contraceptive use among urban youth in Ethiopia. The Ethiopian Journal of Health Development (EJHD), 10.

Shah, I. H. \& Åhman, E. 2012. Unsafe abortion differentials in 2008 by age and developing country region: high burden among young women. Reproductive Health Matters, 20, 169173.

Shaw, E., Levitt, C., Wong, S. \& Kaczorowski, J. 2006. Systematic review of the literature on postpartum care: effectiveness of postpartum support to improve maternal parenting, mental health, quality of life, and physical health. Birth, 33, $210-220$

Shittu, S. B. \& Akinyemi, A. I. 20I7. Determinants of contraceptive use among Hausa migrants in selected urban communities of Osun State, Nigeria. IFE PsychologIA: An International Journal, 25, 266-285.

Staveteig, S. 2016. Understanding unmet need in Ghana: Results from a follow-up study to the 2014 Ghana Demographic and Health Survey. DHS Qualitative Research Studies No. 20. Rockville, Maryland, USA: ICF International.

Subaiya, L. 2007. Internal migration and the use of reproductive and child health services in Peru. DHS Working Papers No. 38. Calverton, Maryland, USA: Macro International.

Sudhinaraset, M., Astone, N. \& Blum, R. W. 2012. Migration and unprotected sex in Shanghai, China: correlates of condom use and contraceptive consistency across migrant and nonmigrant youth. Journal of Adolescent Health, 50, S68-S74.

Tadesse, M., Teklie, H., Yazew, G. \& Gebreselassie, T. 2013. Women's empowerment as a determinant of contraceptive use in Ethiopia: Further analysis of the 201I Ethiopia Demographic and Health Survey. DHS Further Analysis Paper No. 82. Calverton, Maryland, USA: ICF International.

Tam, L. 1994. Rural-to-urban migration in Bolivia and Peru: Association with child mortality, breastfeeding cessation, maternal care, and contraception. DHS Working Papers No. 8. Calverton, Maryland, USA: Macro International.

United Nations 2014. World Urbanization Prospects The 2014 Revision.

United Nations 2015. World population prospects: The 2015 revision. United Nations Econ Soc Aff, 33, I-66.

Uprety, S., Khatri, R., Baral, S. C., Regmi, S. \& Macdonald, M. 2016. Access to family planning 
services by migrant couples in Nepal-barriers and evidence gaps.

Westoff, C. F., Bietsch, K. \& Koffman, D. 2013. Indicators of trends in fertility in sub-Saharan Africa. DHS Analytical Surveys No. 34. Rockville, Maryland, USA: ICF International.

Winter, R., Yourkavitch, J., Mallick, L. \& Wang, W. 2016. Levels and trends in newborn care service availability and readiness in Bangladesh, Haiti, Malawi, Senegal, and Tanzania. DHS Comparative
Reports No. 4I. Rockville, Maryland, USA: ICF International.

Wulifan, J. K., Brenner, S., Jahn, A. \& De Allegri, M. 2016. A scoping review on determinants of unmet need for family planning among women of reproductive age in low and middle income countries. BMC women's health, 16, 2. Zheng, Z. \& Lian, P. Health vulnerability among temporary migrants in urban China. XXV International Population Conference, 2005. 18-23.

\section{Appendix}

Distribution of media exposure's variables by coordinates of the first and second dimensions of the principal component analysis

\begin{tabular}{lcl} 
Variables & $\begin{array}{l}\text { Coordinates of } \\
\text { the } 1^{\text {st }} \\
\text { dimension }\end{array}$ & $\begin{array}{l}\text { Coordinates of } \\
\text { the } 2^{\text {nd }} \\
\text { dimension }\end{array}$ \\
\hline $\begin{array}{l}\text { Frequency of reading newspaper or magazine } \\
\quad \text { Not at all }\end{array}$ & 0.3 & -0.5 \\
$\quad-0.1$ & 0.5 \\
Less than once a week & -0.3 & 0.2 \\
At least once a week & & \\
Frequency of listening to radio & 0.4 & -0.1 \\
$\quad$ Not at all & 0.1 & 0.4 \\
Less than once a week & -0.4 & -0.2 \\
At least once a week & & \\
Frequency of watching television & 0.4 & -0.0 \\
$\quad$ Not at all & 0.2 & 0.4 \\
Less than once a week & -0.4 & -0.3 \\
At least once a week & &
\end{tabular}

Plot of eigenvalue

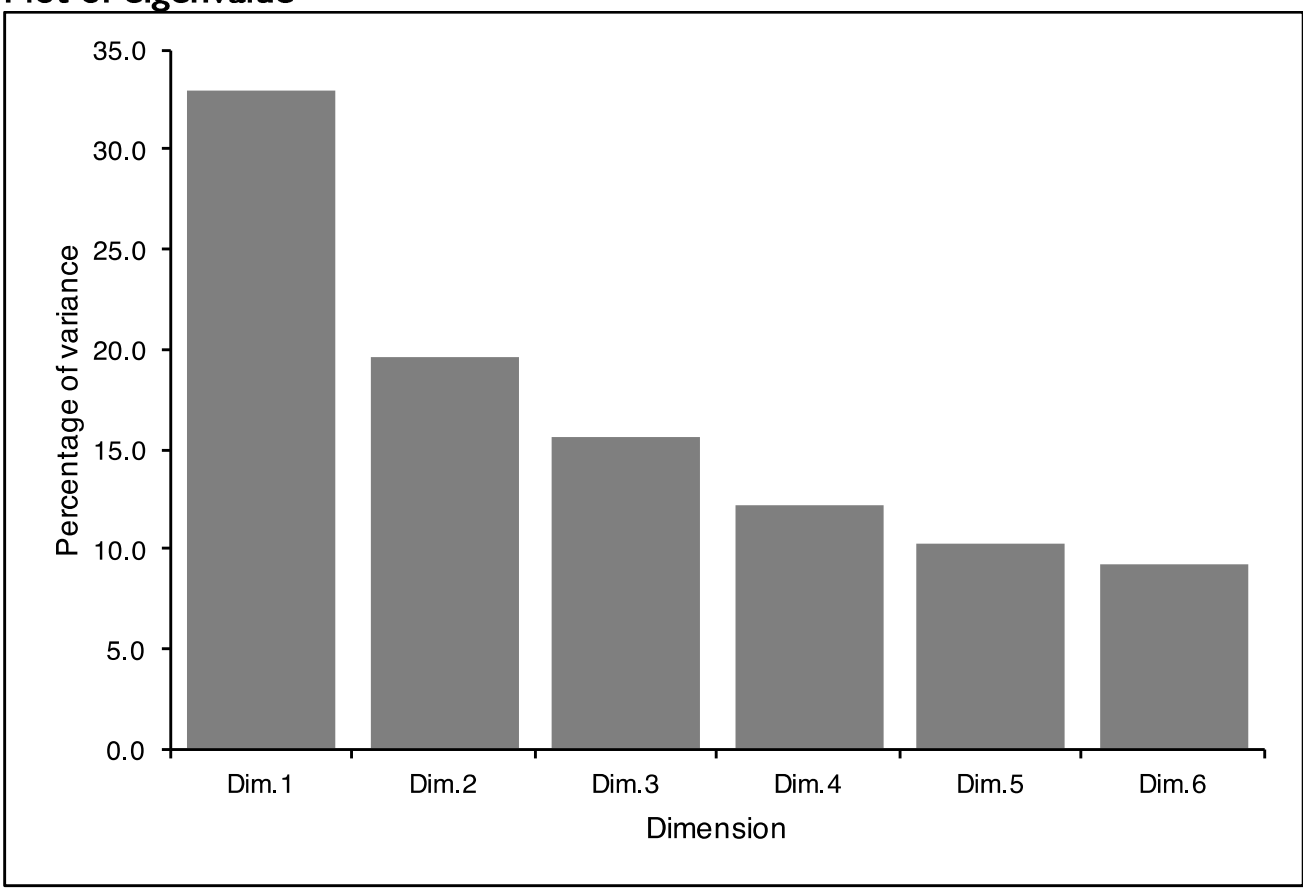

